\title{
Variability in automatically generated raw activity scores
}

\section{Cristina Vargas-Irwin*}

Department of Psychology, Fundación Universitaria Konrad Lorenz, Bogotá, D.C., Colombia

*Correspondence: cvargas@fukl.edu

\section{A commentary on}

Automated assessment of pavlovian conditioned freezing and shock reactivity in mice using the video freeze system.

by Anagnostaras et al. (2010). Front. Behav. Neurosci. 4:158. doi: 10.3389/ fnbeh.2010.00158.

The limitations in the use of raw activity scores in the analysis of conditioned fear are clearly stated by Anagnostaras et al. (2010): raw activity scores such as those provided by the Video-freeze system do exhibit more between-subject variability

${ }^{1}$ Animals were maintained on a $12 / 12 \mathrm{~h}$ light cycle (lights on at 7:00 a.m.), with unlimited access to food and water throughout the experiment. Housing conditions at the Konrad Lorenz University vivarium were all in accordance to the National Institutes of Health "Guide for the Care and use of Laboratory Animals" (2010) and experimental procedures were reviewed and approved by the local IACUC. All data are previously unpublished. than freezing scores. Figure $\mathbf{1}$ shows distributions of automatically generated freezing and activity scores for 44 Swiss Webster mice, which have been transformed into $\mathrm{z}$ scores in order to allow comparisons in a common metric ${ }^{1}$ : Although freezing during baseline was absent for most subjects, raw activity scores do indeed show considerable variance.

This increased variance is not limited to baseline data, but extends to conditioned responding, as can be seen in the righthand side of Figure 1, which compares freezing and raw activity scores for the presentation of a conditioned stimulus (blinking house light), after two lightshock pairings $(0.7 \mathrm{~mA}, 2 \mathrm{~s}$. scrambled foot-shock). This increased variability of raw activity scores in and of itself does not constitute a limitation of this type of data. On the contrary, it may offer a unique opportunity to model individual differences through fear-conditioning preparations: one of the distinctive features of

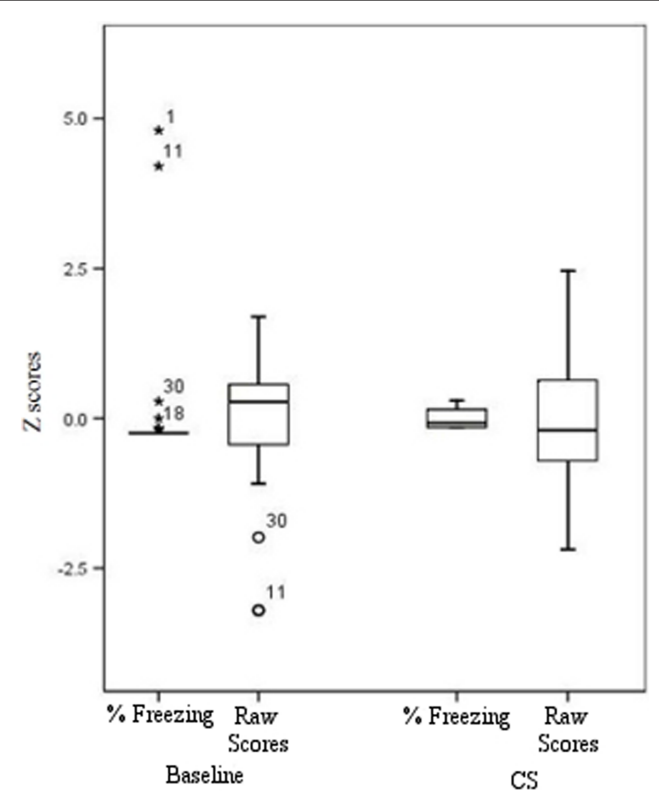

FIGURE 1 | Raw activity and freezing scores under baseline and conditioned stimulus conditions $(\boldsymbol{n}=\mathbf{4 4})$. Raw activity end percent freezing scores (freezing threshold $=18$ ), were automatically generated by the Video-freeze ${ }^{\odot}$ system. Data were then transformed into z scores in older to allow for comparisons between the two scales.

anxiety disorders such as post-traumatic stress syndrome is precisely the variability in the response to stressors. Such betweensubject variation has been successfully replicated in animal models (Bush et al., 2007; Walker et al., 2008).

Raw activity scores may constitute better predictors of response to stressors precisely because of their greater dynamic range, especially when comparing several strains of mice. Incorporating baseline differences into preclinical modeling will indeed require slight departures from current practices in the data analysis of fear-conditioning data (see for example Robles and Vargas-Irwin, 2010), but may by achieved with procedures as straight forward as using raw baseline data as covariates. In summary, analyzing raw scores presents new computational challenges, and further modeling and analytical developments are needed to take advantage of these opportunities.

\section{REFERENCES}

Anagnostaras, S. G., Wood, S. C., Shuman, T., Cai, D. J., Leduc, A. D., Zurn, K. R, Zurn, J. B., Sage, J. R., and Herrera, G. M. (2010). Automated assessment of pavlovian conditioned freezing and shock reactivity in mice using the video freeze system. Front. Behav. Neurosci. 4:158. doi: 10.3389/fnbeh.2010.00158.

Bush, D. E. A., Sotres-Bayon, F., and LeDoux, J. E. (2007). Individual differences in fear: isolating fear reactivity and fear recovery phenotypes. J. Trauma. Stress 20, 413-422.

Robles, J. R., and Vargas-Irwin, C. (2010). Withinsession analysis of the extinction of pavlovian fearconditioning using robust regression. Suma Psicol. 17, 23-34.

Walker, F. R., Hinwood, M., Masters, L., Deilenberg, R. A. and Day, T. A. (2008). Individual differences predict susceptibility to conditioned fear arising from psychosocial trauma. J. Psychiatr. Res. 42, 371-383.

Received: 30 October 2010; accepted: 02 November 2010; published online: 06 December 2010.

Citation: Vargas-Irwin C (2010) Variability in automatically generated raw activity scores. Front. Behav. Neurosci. 4:178. doi: 10.3389/fnbeh.2010.00178

Copyright (c) 2010 Vargas-Irwin. This is an open-access article subject to an exclusive license agreement between the authors and the Frontiers Research Foundation, which permits unrestricted use, distribution, and reproduction in any medium, provided the original authors and source are credited. 